\title{
Ikerketa metabolomikoak haurretan gertatzen den giltzurrun gutxiegitasun kronikoaren diagnostikorako biomarkatzaile berrien identifikazioan
}

\author{
(Metabolomic approaches in the identification of new diagnostic \\ biomarkers in pediatrics with chronic kidney disease)
}

\author{
Sandra Benito ${ }^{1 *}$, Nora Unceta $^{1}$, Alicia Sánchez-Ortega ${ }^{2}$, \\ Alberto Gómez-Caballero ${ }^{1}$, M. Aránzazu Goicolea ${ }^{1}$, Ramón J. Barrio ${ }^{1}$ \\ ${ }^{1}$ Kimika Analitikoa Saila, Farmazia Fakultatea (UPV/EHU) \\ ${ }^{2}$ Analisirako Zerbitzu Zentrala, Lascaray Ikergunea (UPV/EHU)
}

\begin{abstract}
LABURPENA: Giltzurrun gutxiegitasun kronikoaren (GGK) ebaluazioa egiten da iragazpen glomerularraren tasaren (IGT) bidez, eta kalkulatzen da serumeko kreatininaren kontzentrazioan oinarritutako ekuazioen bidez. Hala ere, serumeko kreatinina kontzentrazioa hainbat faktoreren arabera alda daiteke, eta horrek GGKaren diagnostikoa arriskuan jar dezake, bereziki gaixotasunaren fase goiztiarrenetan. Haurretan GGKak, arazo metaboliko eta kardiobaskularrez gain, garapen-arazoak eta malnutrizioa eragiten ditu. Haur osasuntsuekin alderatuta, zailtasun horiek 30 aldiz handitzen dute heriotza-tasa GGKaren fase aurreratuenetan dauden haurretan. Oro har, gaixotasun jakin baterako biomarkatzaileen presentziak diagnostiko goiztiarragoa eta erantzun hobea ahalbidetzen dute. Hori dela eta, GGK pairatzen duten helduetan ikerketa integrala egin da biomarkatzaile berriak topatzeko, baina populazio pediatrikoan ikerlanak oraindik oso mugatuak dira, eta biomarkatzaile berrien beharra dago. Helburu horrekin, haur osasuntsuen eta GGK pairatzen duten haur gaixoen arteko profil metabolikoen konparazioa egin da, metabolomika bideratu zein ez-bideratuak aplikatuz. Ikerketaren ondorioz, GGK pediatrikoaren detekzio goiztiarrean erabilgarri izan daitezkeen zazpi metabolito berri aurkitu dira, kreatinina biomarkatzaile klasikoarekin batera. Metabolito horiek, kreatininarekin batera erabiliz, kreatinina soilaren erabilerarekin ez bezala, haur gaixoak eta osasuntsuak bereiztea ahalbidetzen dute.
\end{abstract}

HITZ GAKOAK: giltzurrun gutxiegitasun kronikoa, metabolomika, biomarkatzaileak, likido kromatografia-masa espektrometria.

ABSTRACT: The assessment of chronic kidney disease (CKD) is performed by means of glomerular filtration rate (GFR), which is calculated from equations using serum creatinine concentration. However, serum creatinine concentration changes according to several factors, and this might endanger CKD diagnosis, especially in early stages of the disease. In addition to metabolic and cardiovascular complications, CKD is related to growth complications and malnutrition. All of these complications lead to a 30 times higher mortality rate in paediatrics suffering from advanced CKD compared to healthy counterparts. Overall, the existence of biomarkers for a defined disease allows earlier diagnosis as well as better response. For that reason, comprehensive research has been performed in adults suffering from CKD aimed at finding new biomarkers, however only a few studies are available in paediatrics with CKD so far, and there is a need for new biomarkers in this population. For that purpose, following targeted and untargeted metabolomics approaches seven potential biomarkers have been found which could be useful for paediatric CKD by comparing metabolic profiles. The use of these metabolites in addition to creatinine enables better differentiation of paediatrics with CKD and control ones, unlike just creatinine itself.

KEYWORDS: metabolomics, biomarkers, liquid chromatography-mass spectrometry, chronic kidney disease.

* Harremanetan jartzeko / Corresponding author: Sandra Benito, Farmazia Fakultatea (UPV/EHU), Unibertsitateko Ibilbidea, 7, 01006 Vitoria-Gasteiz, Euskal Herria. - sandra.benito@ehu.eus - https://orcid.org/0000-0002-0066-0303.

Nola aipatu / How to cite: Benito, Sandra; Unceta, Nora; Sánchez-Ortega, Alicia; Gómez-Caballero, Alberto; Goicolea, M. Aránzazu; Barrio, Ramón J. (2020). «lkerketa metabolomikoak haurretan gertatzen den giltzurrun gutxiegitasun kronikoaren diagnostikorako biomarkatzaile berrien identifikazioan»; Ekaia, 37, 2020, 65-81. (https://doi.org/10.1387/ekaia.20859).

Jasoa: 15 maiatza, 2019; Onartua: 24 urria, 2019.

ISSN 0214-9001 - eISSN 2444-3255 / (c) 2020 UPV/EHU

(c) () () Obra hau Creative 
Sandra Benito, Nora Unceta, Alicia Sánchez-Ortega, Alberto Gómez-Caballero, M. Aránzazu Goicolea, Ramón J. Barrio

\section{SARRERA}

Giltzurrun gutxiegitasun kronikoa (GGK) da giltzurrunek beren zeregina betetzeko duten gaitasunaren galera osoa edo partziala, eta arazo funtzional zein estrukturalen ondorioz gerta daiteke. Hortaz, giltzurrunak ez dira gai odola behar beste iragazteko, eta odolean hondakinen metaketa gertatzen da, zeinak osasunean kalte nabarmenak eragiten baititu [1].

GGKak garapen-zailtasunak, zailtasun metaboliko eta kardiobaskularrak eragiten ditu haurretan, eta ordezko neurri terapeutikoak hartzera behartzen du sarri (dialisia edo transplantea, kasu) [2]. Nahiz eta osasun terapia berrietan agertutako azken aurrerapenek kontrol eta pronostiko hobeak ahalbidetu dituzten, oraindik ez da posible haurren hazkuntza atzerapena, anemia, metabolismo mineralaren aldaketak eta gaixotasunaren beste zenbait ondorio saihestea, eta arazo kardiobaskularren ondorioz morbilitate eta heriotza-tasa handiak daude populazio talde horietan [3].

Diagnostiko azkarra ezartzeak esku-hartze terapeutiko eraginkorra ahalbidetuko luke, eta, hala, zailtasunen agerpena eta gaixotasunaren progresioa moteldu. Izan ere, diagnostikatu gabeko gaixoen gehiengoa GGKaren fase goiztiarretan dago, eta gaixotasunaren bilakaera alda dezaketen neurri terapeutiko eraginkorrak aplika daitezke. Hala ere, urtero pazienteen kopuru txiki batek giltzurrun gutxiegitasun kroniko terminalerako (GGKT) bidea hartzen du. GGKT pairatzen duten pazienteetan biziraupena bermatzeko ezinbestekoa da giltzurrun ordezko terapia (hemodialisia, dialisi peritoneala edo giltzurrun transplantea) [4].

Gaixotasunaren oinarrizko mekanismo fisiopatologikoak haur zein helduetan berdinak badira ere, GGKaren etiopatologia ezberdina izan ohi da bi populazio horietan. Hori dela eta, GGK pediatrikoa zenbaitetan entitate nosologiko independentetzat hartu izan da [4]. European Society for Pediatric Nephrology (ESPN) eta European Renal Association and European Dialysis and Transplantation Association (ERA-EDTA) erakundeek 2009 eta 2011 bitartean giltzurrun ordezko terapia jasotzen zuten haurren prebalentzia ikertu zuten. Europako 37 herrialdetan jasotako datuez baliaturik, 0-14 urte bitarteko miloi bat haurretik 27,9 haurrek giltzurrun ordezko terapia jasotzen dutela jo zen [5]. Gainera, ikusi da heriotza-tasa GGKT duten haurretan 30 aldiz altuagoa dela [3] eta GGKT duten eta giltzurrun ordezko terapia jasotzen duten haurretan 55 aldiz altuagoa, populazio pediatriko orokorrarekin alderatuta [5].

Klinikan, iragazketa glomerularraren tasa (IGT) erabiltzen da giltzurrun funtzioa ebaluatzeko, hau da, giltzurrunetan sortzen den iragazi kantitatea minutuko. IGTk konstantea izan behar du homeostasia mantentzeko. Izan ere, IGT oso altua balitz, organismoarentzat beharrez- 
koak diren substantziak oso azkar pasatuko lirateke giltzurrun tubuluetan zehar, eta birxurgapena ez litzateke behar beste gertatuko; ondorioz, substantzia horiek galtzen dira gernuaren bidez. IGT baxua balitz, berriz, iragazitako gehiena birxurgatuko litzateke, eta, ondorioz, zenbait hondakin produktu ez lirateke era egokian iraitziko [6]. Gaur egun, IGT giltzurrunen funtzioaren adierazle nagusia da, GGK diagnostikatzeko zein GGK fasea zehazteko [7]. IGT zuzenean neurtzeko ez dago modu erraz eta praktikorik; beraz, normalean estimatutako neurketa egiten da, serumean dagoen kreatinina erabiliz biomarkatzaile klasiko gisa. Ordea, kreatinina aparteko biomarkatzaile izatetik urrun dago; izan ere, beraren sentikortasuna nahiko mugatua da, eta, nefronen (giltzurrunen unitate funtzionalen) funtzioaren galera handia den arte ez du kalterik detektatzen. Horrez gain, faktore anitzek eragiten dute kreatininaren gorputzeko kontzentrazio aldaketan: masa muskularrak, dietak, hidratazio egoerak edo adinak, besteak beste.

Horregatik guztiagatik, GGK pediatrikoan diagnostikoa egitea edo gaixotasunaren bilakaerari jarraitzea ahalbidetzen duten biomarkatzaile berrien identifikazioa beharrezkoa da, haurretan gaixotasun horren fisiopatologia eta bilakaera sakon ulertzeko eta diagnostiko goiztiarra hobetzeko [8].

\section{IKERKETA METABOLOMIKOAK GGK PEDIATRIKOAN}

Teknologia «omiko»en agerpenak ekarri du ikerketa biomedikoaren iraultza; izan ere, gaixotasun ezberdinetarako biomarkatzaile berrien aurkikuntza bizkortu du. Teknologia «omiko»en artean genomika, transkriptomika eta metabolomika barne hartzen dira (1. irudia) [9]. Metabolomika da lagin biologikoen metaboloma edo profil metabolikoen azterketa sistematikoa. 1500 Da azpitik dauden molekula txikien ikerketan datza, eta haren helburu nagusia da biomarkatzaileak bilatzea eta identifikatzea [10]. Lagin biologiko horiek era askotakoak izan daitezke, hala nola fluidoak, ehunak edo zelulen kultiboak. Aztergai den taldearen eta kontrol-talde baten arteko profil metabolikoen konparazioan oinarrituta, egoera biologiko batekin erlazionatzen diren zenbait metabolitoren kontzentrazioen aldaketa, igoera edo jaitsiera identifika daiteke. Hortaz, kontzentrazio igoera edo jaitsiera horiek gaixotasun jakinen diagnostikorako erabil daitezke, eta metabolito horietako batzuk biomarkatzaile berri bilaka daitezke. Izan ere, metabolitoak dira zelulen prozesu erregulatzaileen azken erantzuna, eta era askotako konposatuak izan daitezke, hala nola aminoazidoak eta amina biogenikoak, peptido txikiak, karbohidratoak, lipidoak, azido nukleikoak, bitaminak, azido organikoak edo metabolismo energetikoaren metabolitoak [11]. 
Sandra Benito, Nora Unceta, Alicia Sánchez-Ortega, Alberto Gómez-Caballero, M. Aránzazu Goicolea, Ramón J. Barrio

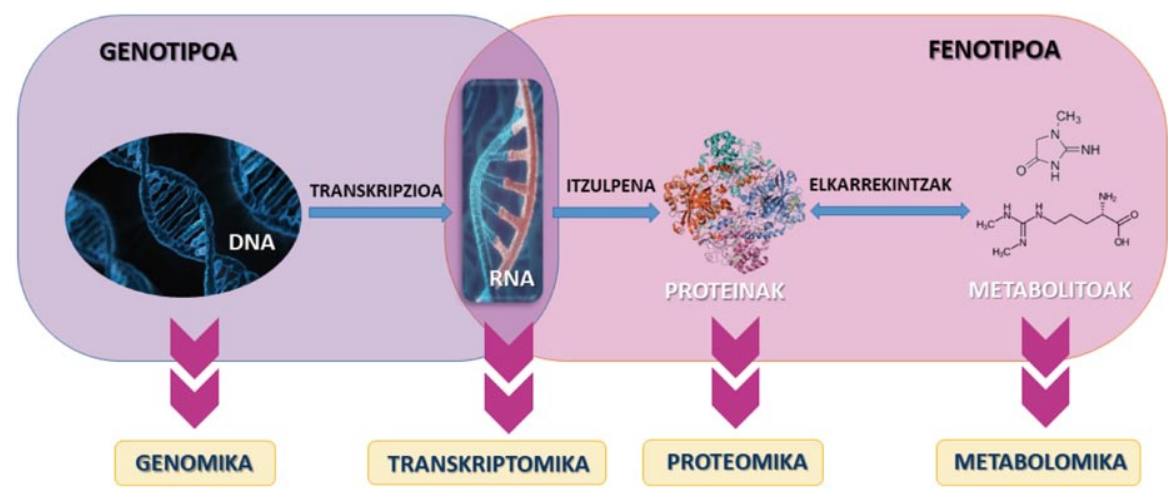

1. irudia. Adar omikoen arteko harremana (genomika, transkriptomika, proteomika eta metabolomika).

Lan honetan zehar GGK haurretan garaiz diagnostikatzeko eta jarraipen egokia egiteko lagungarriak izan daitezkeen biomarkatzaileak ikertzeko erabilitako metabolomika bideratuko (edo targeted) eta metabolomika ez-bideratuko (edo untargeted) estrategiak azaltzen dira [12-14], eta analisi bideratuaren eta ez-bideratuaren arteko onurak eta gabeziak zein diren agerian uzten da. Ikerketa lan honetarako, Gurutzetako Unibertsitate Ospitalean jasotako GGK zuten 3-18 urte bitarteko haurren eta 6-19 urteko haur osasuntsuen plasma erabili da. Plasma laginen ikerketa Gurutzetako Unibertsitate Ospitaleko ikerketa klinikorako batzorde etikoak onartu du (E08/62), eta pazienteen gurasoek baimen idatzia eman dute. Haur osasuntsuak kontroltzat hartzeko, honako onarpen irizpide hauek bete behar izan dituzte: Gurutzetako Unibertsitate Ospitalean kirurgia arina jaso izana. Bazterketa irizpideei dagokienez, anuria, hepatopatia edo diabetes mellitus intsulinodependentea zuten pazienteak baztertu dira.

\subsection{Metabolomika bideratua (targeted metabolomics)}

Metabolomika bideratua oinarritzen da aldez aurretik zehazten diren metabolito ezagunen determinazioan eta kuantifikazioan. Metabolito horiek, bide metaboliko jakinekin, entzima sistemekin edota talde metaboliko jakin batekin erlazionatuta egon daitezke. Analitoak ezagunak direnez, laginaren aurretratamendua ahalik eta sentsibilitate handiena izateko diseinatzen da [11].

Gaur-gaurkoz, metabolomika bideratuak aztertuak ditu giltzurrun transplantea jaso duten haurren eta kontrol osasuntsuen arteko profil ezberdintasunak. Andrade eta lankideek argininaren metilazio zikloan eta 
arginina-kreatina bide metabolikoan parte hartzen duten zenbait metabolitoren (homozisteina, S-adenosilhomozisteina, S-adenosilmetionina, guanidinoazetato eta arginina) profila analizatu dituzte, giltzurrun transplantea jaso duten haurren eta kontrolen plasman. Ikerketa horietatik ondorioztatu da S-adenosilmetionina/S-adenosilhomozisteina metilazio-erlazioa eta dimetilarginina asimetrikoaren kontzentrazioa handituta daudela giltzurrun transplantea jasotako haurretan [16, 17]. Giltzurrun ordezko terapiarik jaso ez duten haur gaixoen eta kontrolen arteko ikerketari dagokionez, Jabs eta lankideek, aldiz, S-adenosilhomozisteinaren eta IGTaren arteko lotura finkatu dute paziente pediatrikoetan [18]. Bestalde, Fleck eta lankideek helduetan egindako ikerketan dimetilarginina asimetrikoaren eta dimetilarginina simetrikoaren eta GGKaren arteko lotura aurkitu zuten [19].

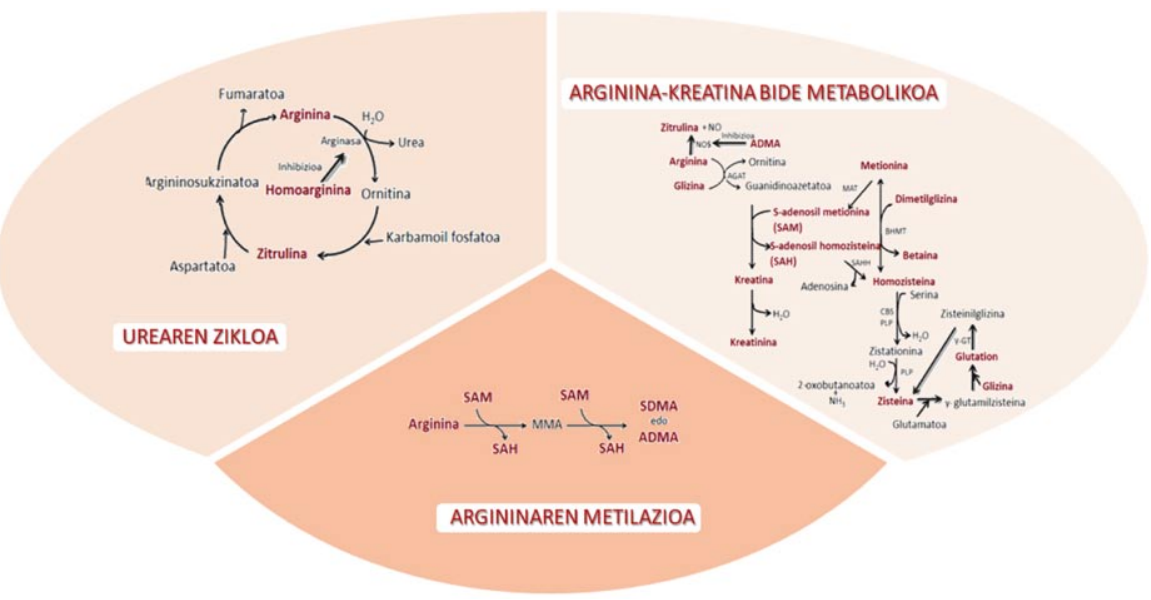

2. irudia. Arginina-kreatina bide metabolikoa, urearen zikloa eta argininaren metilazioa. AGAT: arginina-glizina amidinotransferasa, NOS: oxido nitriko sintasa, MAT: metionina-adenosiltransferasa, SAHH: SAH hidrolasa, BHMT: betaina-homozisteina S-metiltransferasa, PLP: piridoxal fosfatoa, CBS: cistationina beta sintasa, $\gamma$-GT: gamma glutamil transpeptidasa.

1. taulan, GGK duten gaixoetan, haur zein heldu, egin diren ikerketa metabolomiko bideratuak bildu dira. Datu horietan oinarrituz, urearen zikloan, argininaren metilazioan eta arginina-kreatina bide metabolikoetan parte hartzen duten 16 aminoazido, aminoazidoen eratorri eta erlazionatutako metabolito aukeratu dira: dimetilarginina asimetrikoa, arginina, betaina, zitrulina, kreatina, zisteina, dimetilglizina, glutation, glizina, homoarginina, homozisteina, metionina, S-adenosilhomozisteina, S-adenosilmetionina eta kreatinina (2. irudia) [12]. Konposatu ho- 
rien profil metabolikoa analizatu da giltzurrun ordezko terapia jasotako zein ez jasotako haur gaixo eta haur osasuntsuen plasma laginetan. Horretarako, metabolomika metodo bideratu bat garatu eta balioztatu da likido kromatografia-masa espektrometria bidez kuadrupolo-hegaldi denbora analizatzailearekin (LC-QTOF). Oro har, metabolomika metodo bideratuek ondorengo urratsak egiten dituzte: metodo instrumentalaren eta laginen prestaketaren optimizazioa analizatu nahi diren metabolito espezifikoetarako, analisiaren kalitatea bermatzeko metodo analitikoaren baliozkotzea, eta, azkenik, laginen analisia eta emaitzen analisi estatistiko edo kimiometrikoa.

1. taula. Plasma kontzentrazio handituak edo gutxituak izan ditzaketen susmoa duten metabolitoak aurretiko ikerketen arabera

\begin{tabular}{|c|c|c|c|}
\hline Analitoa & Populazioa & Kontzentrazioa odolean GGKean & Erreferentzia \\
\hline \multirow{4}{*}{ ADMA } & Haurrak & $\begin{array}{l}\text { Handituta transplantea jaso duten pazien- } \\
\text { teetan }\end{array}$ & Andrade, 2011 [13] \\
\hline & Helduak & $\begin{array}{l}\text { Handituta, kreatinina serikoarekin eta ira- } \\
\text { gazpen tasa glomerularrarekin korrela- } \\
\text { zionatuta }\end{array}$ & Fliser, 2005 [36] \\
\hline & Helduak & $\begin{array}{l}\text { Handituta GGKdun paziente guztietan } \\
\text { kontrol osasuntsuekin alderatuz }\end{array}$ & Fleck, 2003 [16] \\
\hline & Helduak & Handituta (maila bikoiztuta GGKTan) & Marescau, 1997 [37] \\
\hline \multirow{3}{*}{ ARG } & Haurrak & ARG/ADMA erlazio baxua & Andrade, 2011 [13] \\
\hline & Sprague-Dawley arratoiak & $\begin{array}{l}\text { Sintesia gutxituta giltzurrunetan (badi- } \\
\text { rudi beste organoren batek konpentsa de- } \\
\text { zakeela) }\end{array}$ & Chen, 2010 [38] \\
\hline & Helduak & Gutxituta GGK graduarekin harremanean & Fleck, 2003 [16] \\
\hline \multirow{2}{*}{ BET } & Helduak & Paziente uremikoetan handituta & Mutsaers, 2013 [39] \\
\hline & Helduak & Gutxituta giltzurrun gaixotasunetan & Lever, 1994 [40] \\
\hline CIT & Sprague-Dawley arratoiak & Handituta neurri batean & Chen, 2010 [38] \\
\hline CTN & Helduak & $\begin{array}{l}\text { Handituta dialisiarekin tratamenduan dau- } \\
\text { den paziente uremikoetan }\end{array}$ & De Deyn, 1986 [41] \\
\hline CYS & Helduak & $\begin{array}{l}\text { Zisteina totala eta askea handituta bai gil- } \\
\text { tzurrunen ordezko terapia jasotako zein ez } \\
\text { jasotako pazienteetan }\end{array}$ & Suliman, 1997 [42] \\
\hline \multirow[b]{2}{*}{ DMG } & Helduak & $\begin{array}{l}\text { 3. eta 4. graduetako GGK duten pazientee- } \\
\text { tan handituta kontrolekin alderatuta }\end{array}$ & Mutsaers, 2013 [39] \\
\hline & Helduak & $\begin{array}{l}\text { Handitzen da giltzurrun funtzioa gutxitu } \\
\text { ahala. Dialisian dauden pazienteetan } 2 \text { edo } \\
3 \text { aldiz handituta egon daiteke }\end{array}$ & McGregor, 2001 [43] \\
\hline
\end{tabular}


Ikerketa metabolomikoak haurretan gertatzen den giltzurrun gutxiegitasun kronikoaren diagnostikorako biomarkatzaile berrien identifikazioan

\begin{tabular}{|c|c|c|c|}
\hline Analitoa & Populazioa & Kontzentrazioa odolean GGKean & Erreferentzia \\
\hline GSH & Haurrak & $\begin{array}{l}\text { Gutxituta dialisi peritoneala jasotzen du- } \\
\text { ten haurretan, haur populazio kontrol ba- } \\
\text { ten aldean }\end{array}$ & Zwolinska, 2009 [44] \\
\hline \multirow{3}{*}{ GLY } & Haurrak & $\begin{array}{l}\text { Handituta transplantea jaso duten hau- } \\
\text { rretan }\end{array}$ & Andrade, 2011 [13] \\
\hline & Helduak & $\begin{array}{l}\text { Handituta hemodialisiaren aurretik eta dia- } \\
\text { lisi peritoneal jarraitua jasotzen duten pa- } \\
\text { zienteetan }\end{array}$ & Chuang, 2006 [45] \\
\hline & Wistar arratoi arrak & $\begin{array}{l}\text { Arinki handituta GGKan bai azidosia du- } \\
\text { ten bai azidosia ez duten pazienteetan }\end{array}$ & Holecek, 2001 [46] \\
\hline \multirow{3}{*}{ HARG } & Helduak & $\begin{array}{l}\text { HARG kontzentrazio baxua GGK goiztia- } \\
\text { rraren adierazle izan daiteke }\end{array}$ & Drechsler, 2013 [47] \\
\hline & Helduak & $\begin{array}{l}\text { HARG mailak gutxitzen dira giltzurrun } \\
\text { gaixotasuna larritu ahala }\end{array}$ & Ravani, 2013 [48] \\
\hline & Helduak & Gutxituta & Marescau, 1997 [37] \\
\hline \multirow{3}{*}{ HCYS } & Haurrak & $\begin{array}{l}\text { HCYS handitu zen transplantatutako zein } \\
\text { ez transplantatutako GGKdun haurretan }\end{array}$ & $\begin{array}{l}\text { Andrade, } 2011[13] \\
\text { Andrade, } 2008[14]\end{array}$ \\
\hline & Haurrak & HCYS totala plasman handituta & Merouani, 2001 [49] \\
\hline & Haurrak & $\begin{array}{l}\text { HCYS totala eta librea handituta bai gil- } \\
\text { tzurrun ordezko terapia jasotzen zuten bai } \\
\text { jasotzen ez zuten GGKdun haurretan }\end{array}$ & Suliman, 1997 [42] \\
\hline \multirow{3}{*}{ MET } & Haurrak & $\begin{array}{l}\text { Paziente hemodializatuetan gutxituta dago } \\
\text { kontrol taldearekin alderatuta }\end{array}$ & El Sawy, 2012 [50] \\
\hline & Wistar arratoi arrak & $\begin{array}{l}\text { Gutxituta GGK duten arratoietan kontrol } \\
\text { taldearekin alderatuta }\end{array}$ & Holecek, 2001 [46] \\
\hline & Helduak & $\begin{array}{l}\text { Gutxituta dialisi peritoneal jarraitua, he- } \\
\text { modialisia jasotzen duten pazienteetan } \\
\text { zein dialisia jaso ez duten paziente ure- } \\
\text { mikoetan }\end{array}$ & Suliman, 1997 [42] \\
\hline \multirow{3}{*}{$\mathrm{SAH}$} & Haurrak & Handituta transplantatutako haurretan & Andrade, 2011 [13] \\
\hline & Helduak & Handituta & Loehrer, 1998 [51] \\
\hline & Helduak & Handituta & Perna, 1996 [52] \\
\hline SAM & Helduak & $\begin{array}{l}\text { SAM handituta eta SAM/SAH metilazio } \\
\text { indizea gutxituta GGKT duten pazien- } \\
\text { teetan }\end{array}$ & Loehrer, 1998 [51] \\
\hline \multirow[b]{2}{*}{ SDMA } & Helduak & $\begin{array}{l}\text { Handituta, CNN serikoarekin eta glomeru- } \\
\text { luen iragazte tasarekin korrelazionatuta }\end{array}$ & Fliser, 2005 [36] \\
\hline & Helduak & $\begin{array}{l}\text { Handituta giltzurrunen ordezko terapia ja- } \\
\text { sotzen duten zein jasotzen ez duten pazien- } \\
\text { teetan kontrol osasuntsuekin alderatuta }\end{array}$ & Fleck, 2003 [16] \\
\hline
\end{tabular}


Sandra Benito, Nora Unceta, Alicia Sánchez-Ortega, Alberto Gómez-Caballero, M. Aránzazu Goicolea, Ramón J. Barrio

Metodo honen garapenerako zenbait zailtasun gainditu behar izan dira, hala nola zenbait aminoazidoren polaritatea edo aminoazidoetako batzuen oxidatzeko joera. Izan ere, aipatutako metabolitoetako batzuk oso txikiak eta polarrak izanik, likido-kromatografia bidez analizatu ahal izateko, azido perfluoroheptanoikoa gehitu behar izan zaio fase mugikorrari, analito horien atxikipena gerta dadin. Horrez gain, aminoazidoetako batzuk aminotiolak direnez gero, ditiotreitol agente erreduktorea erabili behar izan da aminoazido horien kuantifikazio totala ahalbidetzeko. Laginen tratamendua, metabolito ezagun hauen analisira bideratzen denez, oso espezifikoa da. Hala, bada, ondorengo urratsak definitu dira. Lehenik eta behin, $50 \mu \mathrm{L}$ plasma lagin izanik, $10 \mu \mathrm{L}$ barne-estandar gehitzen zaizkio lagin tratamenduan gerta daitezkeen aldaketak zuzentzeko eta $50 \mu \mathrm{L}$ ditiotreitol $77.000 \mathrm{mg} \mathrm{L}^{-1}$ gaineratzen zaizkio. Nahasketa hori 15 minutuz inkubatu eta gero, $150 \mu \mathrm{L}$ azetonitrilo gehitzen zaizkio, eta zentrifugatzen dira. Azkenik, gainjalkina hartu, nitrogeno korrontean lurrundu eta geratutako hondakina formiato amoniko disoluzio batean disolbatzen da.

Metodo analitikoa behin balioztatu denean, GGK duten 3-18 urte bitarteko 32 haurren eta 6-19 urteko 24 haur osasuntsuren plasman aplikatu da. Garatutako LC-QTOF metodo analitikoa plasma lagin horien analisian aplikatu da. 3. irudian kromatograma bat irudikatu da adibide gisa.

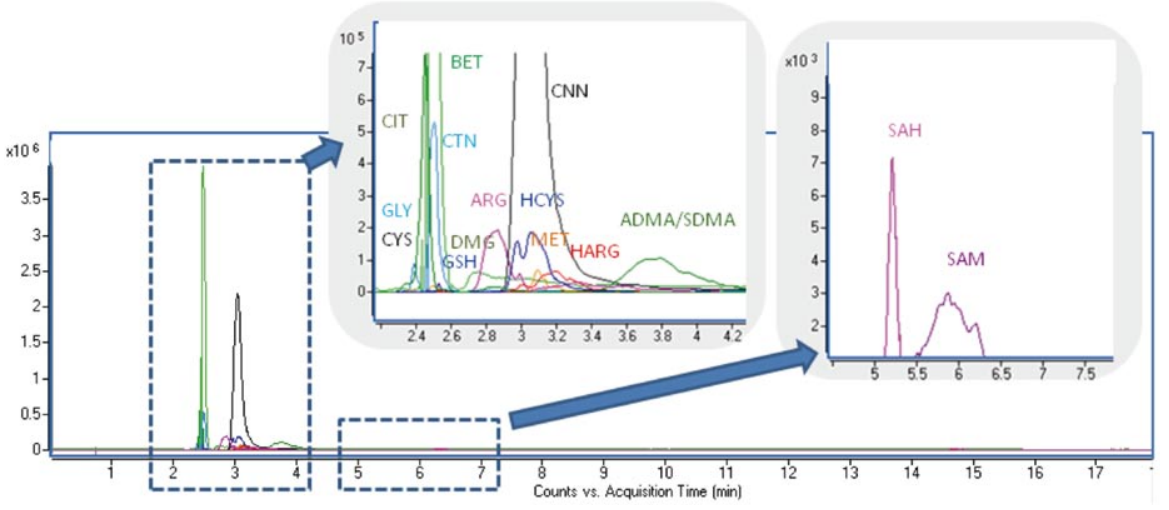

3. irudia. GGK duen paziente pediatriko baten plasma lagin baten kromatograma garatutako LC-QTOF-MS metodo analitikoarekin.

Metabolito bakoitzaren kontzentrazio-datuekin, aldagai bakarreko analisi estatistikoa eta aldagai anitzeko analisi estatistikoa gauzatu dira, metabolito horietako bakoitza biomarkatzaile gisa erabiltzeko esanguratsua izan daitekeen jakiteko asmoz. Aldagai bakarreko analisiak haur gaixo eta osasuntsuen arteko ezberdintasunak azaleratu ditu honako metabolito hauei dagokienez: glizina, zitrulina, kreatinina, dimetilarginina asimetrikoa, dimetilarginina simetrikoa eta dimetilglizina. 
Aldagai anitzeko analisiak, ordea, GGK zuten pazienteen plasman zenbait metabolitoren kontzentrazioa altuagoa zela erakutsi du; zitrulinaren, S-adenosilmetioninaren eta dimetilarginina simetrikoaren kontzentrazioak, hain zuzen. Hortaz, biomarkatzaile berri posibletzat hartu dira, kreatininarekin batera (4a. irudia). Izan ere, karratu minimoen erregresio linealean eta bereizkuntzaanalisian (PLS-DA) oinarrituz, proposatzen diren biomarkatzaile horiek kasuen \% 89tan gai izango lirateke gaixotasunaren lehen faseetan dauden haur gaixo eta osasuntsuak bereizteko; kreatininak bakarrik, aldiz, kasuen \% 71tan egingo luke pazienteen sailkapen zuzena. Gainera, analito horien kontzentrazioaren eta gaixotasunaren fasearen artean mailaketa bat aurkitu izan da. Horrez gain, gaixotasunaren fasea kontuan izaten ez bada, 4 metabolito horiek kontrolen eta GGK duten haurren arteko sailkapena kasuen \% 10etan hobetzen dute, kreatininaren erabilerarekin alderatuz (4b. irudia) [13].
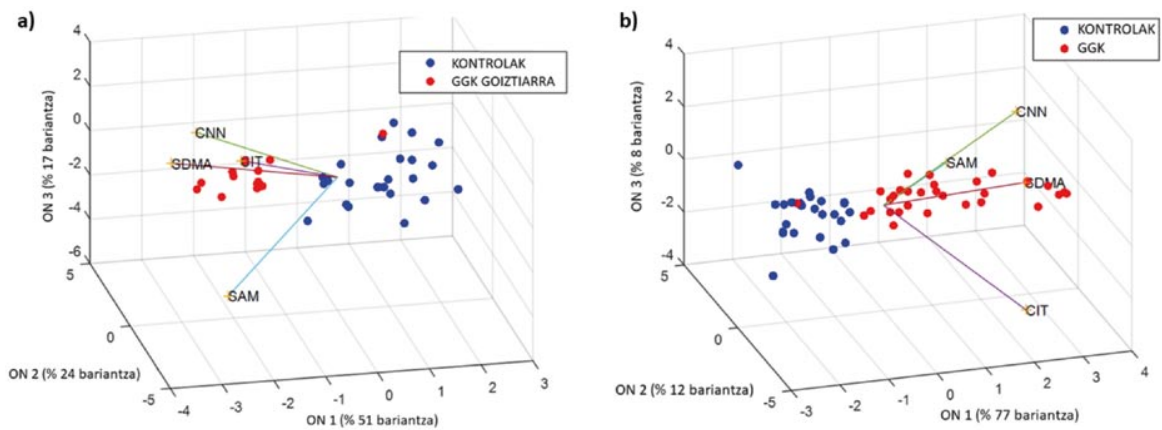

4. irudia. Osagai nagusien analisia 4 metabolitoekin ahalbidetzen duen bi populazioen sailkapena, bai GGK goiztiarra (4a irudia) bai GGK edozein fasetan duten paziente pediatrikoak eta kontrolak alderatuta ( $4 \mathrm{~b}$ irudia).

Arrazoi horiek direla eta, egileek ikerketa honetan aurkitu diren hiru metabolito berri horiek, kreatininarekin batera baheketa frogetan erabiltzen diren ekuazioetan sartzea proposatzen dute. Horrela, nefrologoek egin ohi duten gaixotasunaren diagnostikoa familiako medikuak aurreikus lezake, pazienteak duen GGK fasea iragarri ahal izateko mediku espezialistarenera bidali aurretik.

\subsection{Metabolomika ez-bideratua (untargeted metabolomics)}

Metabolomika ez-bideratuaren helburua da jatorri desberdinetako lagin taldeen artean ahalik eta metabolito gehienak konparatzea, aldez aurretik hautaketarik egin gabe, esanguratsuak diren metabolitoak soilik identifikatzeko. Oro har, erresonantzia magnetiko nuklearra eta masa espektrometriaren aplikazioan oinarritzen dira, nahiz eta joera masa espektrometriaren aldekoa den; izan ere, masa espektrometria sentikortasun handiko teknika analitikoa da 
Sandra Benito, Nora Unceta, Alicia Sánchez-Ortega, Alberto Gómez-Caballero, M. Aránzazu Goicolea, Ramón J. Barrio

kontzentrazio ezberdinetan dauden metabolito esanguratsuak identifikatzeko [20]. Masa espektrometrian oinarritutako ekipamendu analitiko ezberdinen artean goraipatu beharra dago bereizmen altuko masa espektrometriaren garrantzia (QTOF erako ekipoak, kasu); izan ere, horiek baino ez dute ezezagunak diren konposatu berriak identifikatzeko era ematen.

Metabolomika ez bideratuan lan-fluxu jakin bati jarraitzen zaio: laginketa eta laginen prestaketa, laginen analisia, datuen aurreprozesatzea (zarata ezabatzeko, kromatogramaren tontorrak detektatu eta lerrokatzeko), eta, azkenik, datuen analisi estatistiko eta kimiometrikoa egiten da (5. irudia). Behin adierazgarriak diren metabolitoak ezagututa, horien identitatea datu-baseetan aztertuko da, eta, azkenik, izangaien patroiak analizatuko dira, eta lagineko entitateen atxikipen denbora, masa zehatza eta MS/ MS, espektroarekin konparatuko dira. Kasu honetan, bai laginen prestaketa bai laginen analisia ahalik eta metabolito seinale gehien lortzera bideratzen dira, eta, hori dela eta, prozedura ahalik eta sinpleenak erabiltzen dira metabolomika ez-bideratuan.

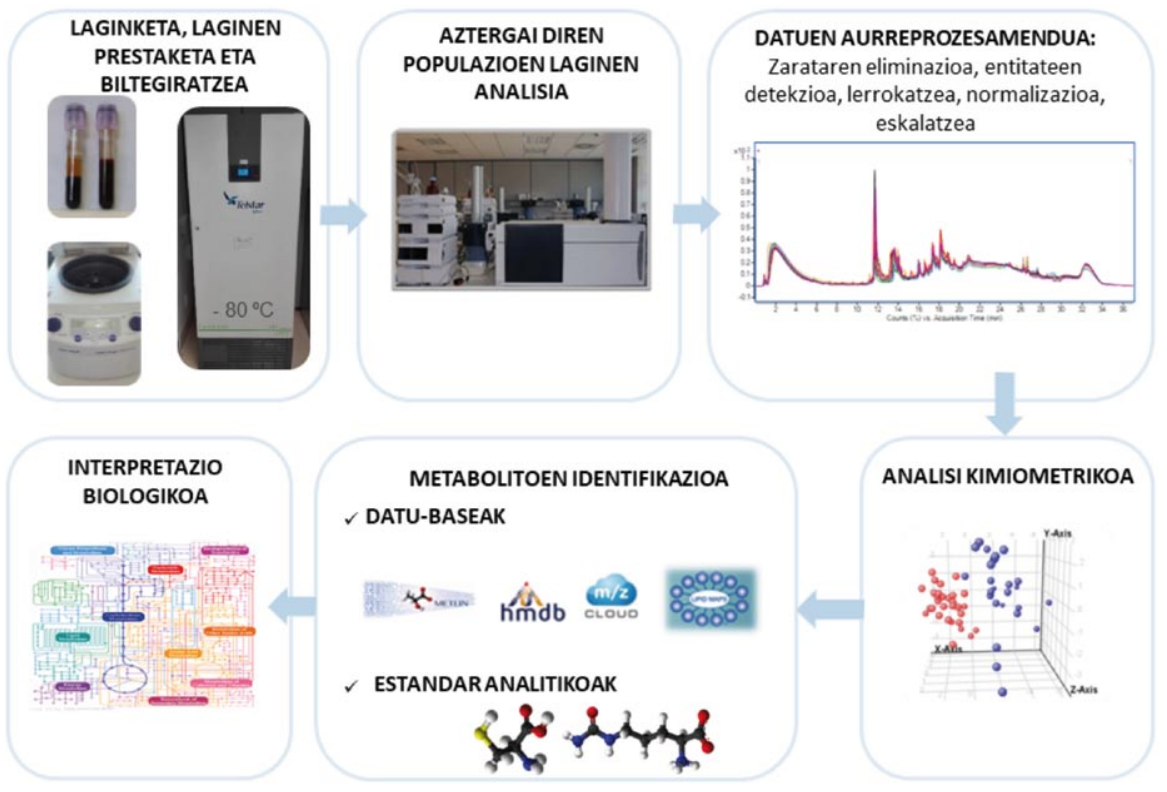

5. irudia. Metabolomika metodo ez-bideratuek jarraitu ohi duten lan-fluxua.

Zenbait ikerketa metabolomiko ez-bideratu egin izan dira nefrologia pediatrikoaren esparruan, eta gehiengoak gernua erabili du matrize biologiko gisa, bihotzeko ebakuntzaren ondoriozko giltzurrun gutxiegitasun akutua [21], nefrouropatiak [22] edo xantinuria klasikoa dituzten haur eta hel- 
duen diagnostikorako [23]. Halaber, Zivkovic eta lankideek odola ere erabili izan dute metabolomika metodo ez-bideratuen bidez immunoglobulinarekin erlazionatutako nefropatia ikertzeko [24]. Horrez gain, Sato eta lankideek hemodialisi dosiaren eraginkortasuna aztertzeko GGKT pairatzen duten pazienteen erantzuna aurresan dezaketen markatzaileak ere ikertu dituzte [25].

Haurrek jasandako GGK ikertzeko asmoz, GGK duten 32 haurren eta 26 haur osasuntsuren plasmen metabolomak konparatu dira. Metabolomika ez-bideratuaren helburua ahalik eta metabolito gehien detektatzea denez, laginaren aurretratamenduak ez ditu horiek baztertu behar. Hori dela eta, plasma laginei metanol:etanol $(50: 50, \mathrm{v} / \mathrm{v})$ nahasketa bat soilik gehitu zitzaien proteinak hauspeatzeko. Lagin horiek zuzenean LC-QTOF teknikaren bidez analizatu dira, haur gaixo eta osasuntsuen profil metaboliko plasmatikoak aztertzeko. Era horretan, 232 entitate lortu dira, «masa molekularra@erretentzio denbora» gisa izendatzen direnak, eta horietatik entitate murrizketa egin behar da kimiometriaren bidez. Metabolomika ez-bideratuaren kasuan nahitaezkoa da analisi kimiometrikoaren erabilera; izan ere, detektatutako entitate kopurua izugarria denez, adierazgarriak izan litezkeen entitateak ezagutu eta identifikatu behar dira. Kontuan izanik erabilitako kimiometria metodologiak lortutako entitate esanguratsu kopurua alda dezakeela, bi metodo kimiometriko erabiltzea erabaki da, bata karratu minimoen erregresio linealean eta bereizkuntza-analisian funtsa duen metabolito murrizketan oinarritua (SPLS-DA); bestea, ordea, talde bakoitzean metabolitoen agerpen maiztasuna eta seinale intentsitatea esanguratsuak diren aztertzen du $t$-student froga estatistikoan oinarrituz. Lehenbiziko kasuan, Matlab (Mathworks ${ }^{\circledR}$ ) softwarea erabili da, eta, bigarrenean, aldiz, Mass Profiler Professional (Agilent Technologies $\left.{ }^{\circledR}\right)$. Bi metodo kimiometriko horiek aplikatu direnean, bi metodologietan komunak ziren entitateak bakarrik aukeratzea erabaki da biomarkatzaile gisa proposatzeko [14]. Era horretan, GGK duten haurren eta haur osasuntsuen metabolomen artean estatistikoki desberdinak diren 5 entitate aurkitu dira: 125,0836@1,32; 231,1477@1,32; 313,2242@12,15; 246,2333@15,61 eta 584,2613@12,46. Entitate horien erabilerak GGK gaixoen eta kontrolen arteko bereizkuntza ahalbidetzen du \% 96ko igartze-mailarekin. Gainera, gaixotasunaren fase goiztiarretan zeuden pazienteetan bost biomarkatzaile horiek erabiltzean laginen \% 97 ongi sailkatzea lortu da. Metabolito horiek biomarkatzaile gisa itxaropentsuak izan litezkeela kontuan izanik, masa-espektrometria datubaseen bidez, MS/MS espektroaren azterketaren bidez eta estandar analitikoen bidez identifikatzeko saiakera egin da. Bost metabolito horien artean lau identifikatzea posible izan da, konfiantza maila altuenarekin Metabolomics Standards Initiative estandarren arabera [26]: $n$-butirilkarnitina, cis-4dezenoilkarnitina, bilirrubina eta esfingosina-1-fosfato (2. taula). Ikerketa horren arabera, GGK duten haurren plasman, $n$-butirilkarnitina, cis-4-dezenoilkarnitina eta esfingosina-1-fosfato metabolitoen kontzentrazioa handituta egongo litzateke, eta bilirrubinaren maila gutxituta. 


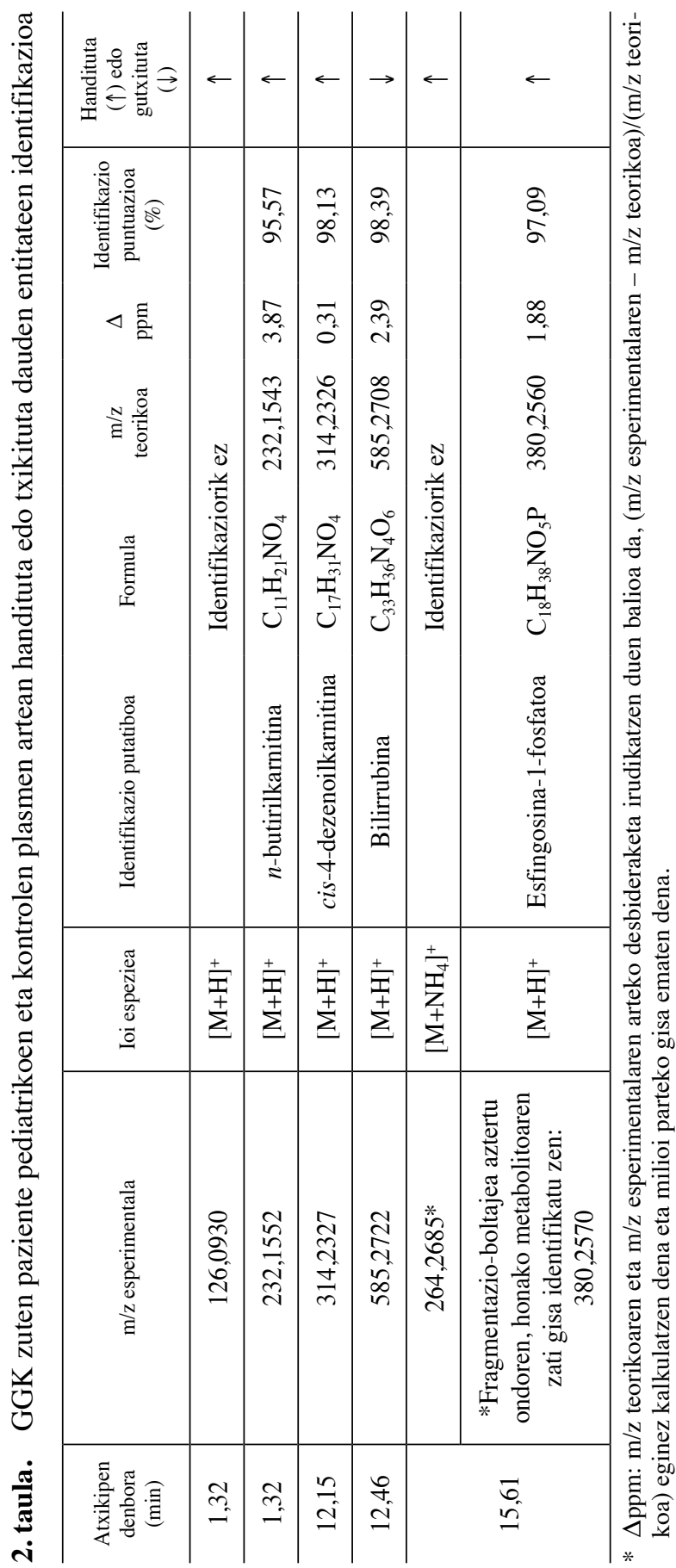




\section{EMAITZEN INTERPRETAZIO BIOLOGIKOA}

GGK duten paziente pediatrikoen eta adin bereko kontrolen plasma profilak metabolomika bideratuaren bidez ikertu ondoren, kreatinina biomarkatzaile klasikoaz gain, zitrulina, dimetilarginina simetrikoa eta S-adenosilmetionina proposatu dira biomarkatzaile berri gisa. Aldiz, metabolomika ez-bideratuaren bidez $n$-butirilkarnitina, cis-4-dezenoilkarnitina, bilirrubina eta esfingosina-1-fosfatoa identifikatu dira biomarkatzaile berri gisa. Proposatutako zazpi biomarkatzaile berri horiek literatura zientifikoarekin alderatu dira metabolitoen kontzentrazio igoerak edo jaitsierak azal dezaketen interpretazio biologikoak aurkitzeko asmoz.

Andrade eta lankideen arabera, zitrulinaren handitzea gaixotasunarekin erlazioa duen arginina/glizina amidinotransferasa entzimen aktibitate baxuak azaldu lezake [17]. Dimetilarginina simetrikoari dagokionez, metabolito hori batez ere gernuaren bidez iraizten da, eta, hortaz, plasmako dimetilarginina simetrikoaren pilaketa iraizketa urriaren ondorio izan liteke [27]. Bestalde, giltzurrunek paper garrantzitsua dute homozisteina eta antzeko aminotiolen metabolismoan. Valli eta lankideen ikerketen arabera, S-adenosilmetioninak homozisteinaren mailarekiko dependentzia du, eta nahiz eta homozisteinaren eta IGTaren artean korrelaziorik ez aurkitu, S-adenosilmetioninaren eta IGTaren artean erlazioa dago [28].

Calvani eta lankideek egindako ikerketen arabera, plasman $n$-butirilkarnitina eta cis-4-dezenoilkarnitina bezalako azilkarnitinak metatzea esterifikatutako karnitina frakzioaren giltzurrun iraizketaren gutxitzearekin erlazionatuta egongo litzateke [29]. Sirolli eta lankideek hemodialisiarekin denbora luzez tratamenduan dauden eta GGKT duten paziente helduetan karnitina askeen mailaren gutxitzea eta azilkarnitinen handitzea ikusi dute plasman, eta identifikatutako azilkarnitinen artean butirilkarnitina dago (isomeroen arteko bereizketarik egin ez bazen ere) [30].

Esfingosina-1-fosfatoa seinalizazio lanetan aritzen den esfingolipidoa da, zenbait bide metaboliko erregulatzailetan parte hartzen duena eta prozesu fisiopatologiko ezberdinetan paper garrantzitsua duena (arteriosklerosian, minbizian, diabetean eta osteoporosian, kasu) [31]. Esfingosina-1fosfatoaren 1 hartzailearen (S1P1R) aktibazioak arratoietan giltzurrunaren hantura blokeatzen duela ikusi da, eta badirudi nefropatia diabetikoa arin lezakeela [32]. Horrez gain, GGK gaixotasunerako biomarkatzaile gisa beste ikertzaile batzuek proposatu duten TGF- $\beta 1$ askapenak ere esfingosina-1-fosfatoaren sorrera susta dezakeela ikusi da [33].

Azkenik, gaixotasunaren izaeragatik metabolitoen pilaketa espero bada ere, bilirrubina biomarkatzaile berri guztien artean gaixoetan gutxituta agertu den bakarra da. Emaitza horiek Sakoh eta lankideek GGKT duten helduetan egindako ikerketarekin bat datoz, zeinetan bilirrubina maila gu- 
Sandra Benito, Nora Unceta, Alicia Sánchez-Ortega, Alberto Gómez-Caballero, M. Aránzazu Goicolea, Ramón J. Barrio

txituak aurkitu baitira paziente gaixoetan [34]. Halaber, bilirrubinak dituen propietate antioxidatzaileak direla eta, horren maila handituak giltzurrunen faktore babesle gisa jardun lezake arratoietan egindako ikerketen arabera [35].

\section{ONDORIOAK}

Gurutzetako Unibertsitate Ospitalean jasotako GGKdun paziente pediatrikoen eta adin bereko kontrolen plasmen metaboloma-profilak metabolomika metodo bideratu zein ez-bideratuen bidez ikertu dira. Lan honen emaitzekin, kreatinina biomarkatzaile klasikoaz gain, beste zazpi biomarkatzaile berri proposatu dira GGK duten haurren diagnostiko goiztiarra egitea ahalbide lezaketenak. Gainera, biomarkatzaile horiek haur gaixoak eta osasuntsuak hobeto bereizteko ahalmena erakutsi dute, baita gainerako GGK faseetan dauden pazienteetan ere.

Ikerketan honetan lortutako emaitzak ikusita, etorkizunean populazio pediatriko ezberdin eta zabalago bat ikertzea proposatzen da zazpi biomarkatzaile horiek GGK duten haurrak eta haur osasuntsuak bereizteko esanguratsuak diren egiaztatzeko.

\section{ESKER ONAK}

Egileek SGIkerren Analisirako Zerbitzu Zentralak (UPV/EHU/FEDER, EU) eskainitako laguntza teknikoa eta giza babesa eskertzen dute. Horrez gain, Gurutzetako Unibertsitate Ospitaleko Metabolismo Sailaren laguntza eskertzen da ikerketarako lagin errealak hornitzeagatik. Sandra Benitok Eusko Jaurlaritzako Hezkuntza, Hizkuntza Politika eta Kultura Sailak emandako doktorego aurreko programaren laguntza (PRE_2013_1_899) eta mugikortasun beka (EP_2016_1_0003) estimatzen ditu. Halaber, Euskal Herriko Unibertsitatearen (UPV/EHU) Ikerketaren Arloko Errektoreordetzak emandako Dokberri 2018-1 programako doktorego osteko beka (DOCREC18/27) eskertzen du.

\section{BIBLIOGRAFIA}

[1] LEVEY, A.S., ATKINS, R., CORESH, J., COHEN, E.P., COLlinS, A.J., ECKARDT, K.U., NAHAS, M.E., JABER, B.L., JADOUL, M., LEVIN, A., POWE, N.R., ROSSERT, J., WHEELER, D.C., LAMEIRE, N. eta EKNOYAN, G., 2007. «Chronic kidney disease as a global public health problem: approaches and initiatives - a position statement from Kidney Disease Improving Global Outcomes». Kidney International, 72, 247-59. 

kronikoaren diagnostikorako biomarkatzaile berrien identifikazioan

[2] THOMAS, R., KANSO, A. eta SEDOR, J.R., 2008. «Chronic kidney disease and its complications». Primary Care: Clinics in Office Practice, 35, 329-44.

[3] HARAMBAT, J., VAN STRALEN, K.J., KIM, J.J. eta TIZARD, E.J., 2012. «Epidemiology of chronic kidney disease in children». Pediatric Nephrology, 27, 363-73.

[4] BECHERUCCI, F., ROPERTO, R.M., MATERASSI, M. eta ROMAGNANI, P., 2016. «Chronic kidney disease in children». Clinical Kidney Journal, 9, 583-91.

[5] CHESNAYE, N. et al. 2014. «Demographics of paediatric renal replacement therapy in Europe: a report of the ESPN/ERA-EDTA registry». Pediatric Nephrology, 29, 2403-10.

[6] El aparato urinario, in Principios de Anatomía y Fisiología, G.J. Tortora and B. Derrickson, Editors. 2011, Editorial Médica Panamericana: Madrid. p. 999-1042.

[7] HUNLEY, T.E., KON, V. eta ICHIKAWA, I., Glomerular Circulation and Function, in Pediatric Nephrology, E.D. Avner, et al., Editors. 2009, Springer: Berlin. p. 46-50.

[8] ZHAO, Y.Y., 2013. «Metabolomics in chronic kidney disease». Clin. Chim. Acta, 422, 59-69.

[9] HASIN, Y., SELDIN, M., LUSIS, A., HASIN, Y., LUSIS, A. eta LUSIS, A., 2017. «Multi-omics approaches to disease». Genome Biol, 18, 83.

[10] FIEHN, O., 2002. «Metabolomics - the link between genotypes and phenotypes». Plant Mol. Biol., 48, 155-171.

[11] BECKER, S., KORTZ, L., HELMSCHRODT, C., THIERY, J. eta CEGLAREK, U., 2012. «LC-MS-based metabolomics in the clinical laboratory». J. Chromatogr. B: Anal. Technol. Biomed. Life Sci., 883-884, 68-75.

[12] BENITO, S., SANCHEZ, A., UNCETA, N., ANDRADE, F., ALDAMIZECHEVARRIA, L., GOICOLEA, M.A. eta BARRIO, R.J., 2016. «LCQTOF-MS-based targeted metabolomics of arginine-creatine metabolic pathway-related compounds in plasma: application to identify potential biomarkers in pediatric chronic kidney disease». Anal. Bioanal. Chem., 408, 747-760.

[13] BENITO, S., SANCHEZ-ORTEGA, A., UNCETA, N., JANSEN, J.J., POSTMA, G., ANDRADE, F., ALDAMIZ-ECHEVARRIA, L., BUYDENS, L.M.C., GOICOLEA, M.A. eta BARRIO, R.J., 2018. «Plasma biomarker discovery for early chronic kidney disease diagnosis based on chemometric approaches using LC-QTOF targeted metabolomics data». J. Pharm. Biomed. Anal., 149, 46-56.

[14] BENITO, S., SANCHEZ, A., UNCETA, N., ANDRADE, F., ALDAMIZECHEVARRIA, L., GOICOLEA, M.A. eta BARRIO, R.J., 2018. «Untargeted metabolomics for plasma biomarker discovery for early chronic kidney disease diagnosis in pediatric patients using LC-QTOF-MS». Analyst, 143, 4448-4458. 
Sandra Benito, Nora Unceta, Alicia Sánchez-Ortega, Alberto Gómez-Caballero, M. Aránzazu Goicolea, Ramón J. Barrio

[15] PATTI, G.J., YANES, O. eta SIUZDAK, G., 2012. «Innovation Metabolomics: the apogee of the omics trilogy». Nat. Rev. Mol. Cell Biol., 13, 263-269.

[16] ANDRADE, F., RODRIGUEZ-SORIANO, J., PRIETO, J.A., AGUIRRE, M., ARICETA, G., LAGE, S., AZCONA, I., PRADO, C., SANJURJO, P. eta ALDAMIZ-ECHEVARRIA, L., 2011. "Methylation cycle, argininecreatine pathway and asymmetric dimethylarginine in pediatric renal transplant». Nephrol. Dial. Transpl., 26, 328-336.

[17] ANDRADE, F., RODRIGUEZ-SORIANO, J., PRIETO, J.A., ELORZ, J., AGUIRRE, M., ARICETA, G., MARTIN, S., SANJURJO, P. eta ALDAMIZ-ECHEVARRIA, L., 2008. "The Arginine-Creatine Pathway is Disturbed in Children and Adolescents With Renal Transplants». Pediatr. Res., 64, 218-222.

[18] JABS, K., KOURY, M.J., DUPONT, W.D. eta WAGNER, C., 2006. «Relationship between plasma S-adenosylhomocysteine concentration and glomerular filtration rate in children». Metab. Clin. Exp., 55, 252-257.

[19] FLECK, C., SCHWEITZER, F., KARGE, E., BUSCH, M. eta STEIN, G., 2003. «Serum concentrations of asymmetric (ADMA) and symmetric (SDMA) dimethylarginine in patients with chronic kidney diseases». Clin. Chim. Acta, 336, 1-12.

[20] SMOLINSKA, A., BLANCHET, L., BUYDENS, L.M.C. eta WIJMENGA, S.S., 2012. «NMR and pattern recognition methods in metabolomics: From data acquisition to biomarker discovery: A review». Anal. Chim. Acta, 750, 82-97.

[21] BEGER, R.D., HOLLAND, R.D., SUN, J., SCHNACKENBERG, L.K., MOORE, P.C., DENT, C.L., DEVARAJAN, P. eta PORTILLA, D., 2008. «Metabonomics of acute kidney injury in children after cardiac surgery». Pediatr Nephrol, 23, 977-84.

[22] ATZORI, L., MUSSAP, M., NOTO, A., BARBERINI, L., PUDDU, M., CONI, E., MURGIA, F., LUSSU, M. eta FANOS, V., 2011. «Clinical metabolomics and urinary NGAL for the early prediction of chronic kidney disease in healthy adults born ELBW». J. Matern.-Fetal Neonat. Med., 24, 41-44.

[23] PERETZ, H., WATSON, D.G., BLACKBURN, G., ZHANG, T., LAGZIEL, A., SHTAUBER-NAAMATI, M., MORAD, T., KEREN-TARDAI, E., GREENSHPUN, V., USHER, S., SHALEV, H., LANDAU, D. eta LEVARTOVSKY, D., 2012. «Urine metabolomics reveals novel physiologic functions of human aldehyde oxidase and provides biomarkers for typing xanthinuria». Metabolomics, 8, 951-959.

[24] ZIVKOVIC, A.M., YANG, J., GEORGI, K., HEGEDUS, C., NORDING, M.L., O'SULLIVAN, A., GERMAN, J.B., HOGG, R.J., WEISS, R.H., BAY, C. eta HAMMOCK, B.D., 2012. «Serum oxylipin profiles in IgA nephropathy patients reflect kidney functional alterations». Metabolomics, $\mathbf{8}$, 1102-1113.

[25] SATO, E., KOHNO, M., YAMAMOTO, M., FUJISAWA, T., FUJIWARA, K. eta TANAKA, N., 2011. «Metabolomic analysis of human plasma from haemodialysis patients». Eur. J. Clin. Invest., 41, 241-55. 
[26] SUMNER, L.W., et al. 2007. «Proposed minimum reporting standards for chemical analysis. Chemical Analysis Working Group (CAWG) Metabolomics Standards Initiative (MSI)». Metabolomics, 3, 211-221.

[27] MIHOUT, F., SHWEKE, N., BIGE, N., JOUANNEAU, C., DUSSAULE, J.-C., RONCO, P., CHATZIANTONIOU, C. eta BOFFA, J.J., 2011. «Asymmetric dimethylarginine (ADMA) induces chronic kidney disease through a mechanism involving collagen and TGF-B1 synthesis». J. Pathol., 223, 37-45.

[28] VAlli, A., CARRERO, J.J., QURESHI, A.R., GARIBOTTO, G., BARANY, P., AXELSSON, J., LINDHOLM, B., STENVINKEL, P., ANDERSTAM, B. eta SULIMAN, M.E., 2008. «Elevated serum levels of S-adenosylhomocysteine, but not homocysteine, are associated with cardiovascular disease in stage 5 chronic kidney disease patients». Clin. Chim. Acta, 395, 106-110.

[29] CALVANI, M., BENATTI, P., MANCINELLI, A., D’IDDIO, S., GIORDANO, V., KOVERECH, A., AMATO, A. eta BRASS, E.P., 2004. «Carnitine replacement in end-stage renal disease and hemodialysis». Ann NY Acad Sci, 1033, 52-66.

[30] SIROLLI, V., ROSSI, C., DI, C.A., FELACO, P., AMOROSO, L., ZUCCHELLI, M., CIAVARDELLI, D., DI, I.C., SACCHETTA, P., BERNARDINI, S., ARDUINI, A., BONOMINI, M. eta URBANI, A., 2012. «Toward personalized hemodialysis by low molecular weight amino-containing compounds: future perspective of patient metabolic fingerprint». Blood Transfus, 10(Suppl 2), s78-88.

[31] MACEYKA, M., HARIKUMAR, K.B., MILSTIEN, S. eta SPIEGEL, S., 2012. «Sphingosine-1-phosphate signaling and its role in disease». Trends Cell Biol., 22, 50-60.

[32] AWAD, A.S., ROUSE, M.D., KHUTSISHVILI, K., HUANG, L., BOLTON, W.K., LYNCH, K.R. eta OKUSA, M.D., 2011. «Chronic sphingosine 1-phosphate 1 receptor activation attenuates early-stage diabetic nephropathy independent of lymphocytes». Kidney Int., 79, 1090-1098.

[33] SONG, J.H., KIM, M., PARK, S.W., CHEN, S.W.C., PITSON, S.M. eta LEE, H.T., 2010. «Isoflurane via TGF- $\beta 1$ release increases caveolae formation and organizes sphingosine kinase signaling in renal proximal tubules». Am. J. Physiol., 298, F1041-F1050.

[34] SAKOH, T., NAKAYAMA, M., TANAKA, S., YOSHITOMI, R., URA, Y., NISHIMOTO, H., FUKUI, A., SHIKUWA, Y., TSURUYA, K. eta KITAZONO, T., 2015. «Association of serum total bilirubin with renal outcome in Japanese patients with stages 3-5 chronic kidney disease». Metab., Clin. Exp., 64, 1096-1102.

[35] BOON, A.C., LAM, A.K., GOPALAN, V., BENZIE, I.F., BRISKEY, D., COOMBES, J.S., FASSETT, R.G. eta BULMER, A.C., 2015. «Endogenously elevated bilirubin modulates kidney function and protects from circulating oxidative stress in a rat model of adenine-induced kidney failure». Sci. Rep., 5, 15482. 